\title{
O CUPUAÇU É NOSSO? ASPECTOS ATUAIS DA BIOPIRATARIA NO CONTEXTO BRASILEIRO
}

\author{
Enio Antunes Rezende ${ }^{1}$ \\ Maria Teresa Franco Ribeiro ${ }^{2}$
}

\section{Resumo}

A partir do estudo de caso do cupuaçu, este trabalho busca apresentar uma análise dos efeitos das atuais práticas de gestão do saber tradicional no Brasil, explorando suas contribuições como subsídio para a construção de uma agenda de governança ambiental global. Para isso buscar-se-á neste trabalho interrogar e discutir o atual debate sobre a biopirataria e gestão do saber tradicional não apenas como uma questão de acesso a esse saber, mas principalmente como uma questão de justiça e eqüidade. O caso cupuaçu destacou-se entre 2003 e 2004 a partir da atuação da ONG acreana AMAZONLINK, que mobilizou uma campanha bem sucedida em protesto ao registro indevido do nome cupuaçu como marca comercial pela empresa japonesa ASAHI Foods, nos escritórios de patente japonês, norte-americano e europeu. Este caso de biopirataria, ainda pouco estudado, é uma referência importante, tanto pelo modo emblemático como revela a lógica e os limites de atuação e articulação dos principais atores envolvidos na questão da governança ambiental global, como também por enfatizar o debate sobre a importância e o uso desses saberes e recursos no Brasil. Adicionalmente, destaca ainda o crescente protagonismo de atores da sociedade civil organizada em ações de proteção e oposição a casos de biopirataria. A abordagem teórica baseia-se no quadro da Ecologia Política, destacadamente, a partir de sua vertente pós-colonial. Com o uso do conceito de zona de contato, aprecia-se a relação entre os diferentes modos de se conhecer e apropriar, desvelando-se a lógica de criação, normalização e operacionalização de conceitos dominantes de conhecimento e propriedade nas tentativas de proteger e promover o saber tradicional. Constatou-se que as atuais formas de gestão desenvolvidas para proteção e promoção do saber tradicional configuram-se como "ilhas" de coordenação que são incapazes de evitar a biopirataria. Um dos efeitos provocados por esse quadro é a marginalização dos sistemas de conhecimento e normas consuetudinárias que regulamentam a reprodução e uso dos saberes tradicionais nas comunidades. No entanto, acredita-se que a maior dificuldade que esse caso revela é que, a concessão de marcas indevidas à terceiros, imputa aos detentores originais e seus aliados o ônus da sua contestação em escritórios de propriedade intelectual. Além de servir de alerta para a

${ }^{1}$ Bolsisista de Pós-doc da Fundação de Apoio à Pesquisa do Estado da Bahia - FAPESB no Núcleo de PósGraduação em Administração - NPGA da Universidade Federal da Bahia - UFBA com o projeto “A gestão do saber tradicional no contexto amazônico: uma análise de iniciativas tripartites Brasil-Peru-Bolívia”, sob a supervisão da Prof. Maria Teresa Franco Ribeiro. Professor Visitante no Departamento de Ciências Biológicas da UEFS. E-mail: enioar@hotmail.com

${ }^{2}$ Doutora em Economia, Pós-doc no l'Institut des Hautes Études de l'Amérique Latine - IHEAL da Université Paris III, professora e pesquisadora em Desenvolvimento e Economia da Inovação no NPGA-UFBA. E-mail: mariatfr@uol.com.br 
necessidade da tipificação legal do crime de biopirataria, o caso do cupuaçu enfatiza a importância do fomento às formas locais de manejo desses saberes e recursos, inclusive o impacto positivo algumas parcerias comerciais avalizadas. Para incrementar a participação interativa dos detentores desses saberes no seu processo de gestão, sugere-se a necessidade de uma abordagem regionalizada, na forma de órgãos ad hoc que incluam ativamente atores nãoestatais; acredita-se que isso permitiria uma apreciação mais adequada das suas especificidades territoriais no desenho das formas de governança sustentáveis para a sua gestão em nível global.

Palavras-chave: Saber Tradicional; Sustentabilidade; Cupuaçu; Biopirataria; Amazonlink.

\section{Abstract}

This paper presents a critical understanding of the traditional knowledge (TK) promotion and protection practices implemented by the Brazilian State through the analysis of the cupuaçu case. The debate about TK's indebt appropriation is approached not only as a matter of access, but mainly as a justice and equity issue, exploring how these practices could contribute for the global environmental agenda. The cupuaçu case happened between 2003 and 2004, when the Brazilian NGO Amazonlink organized a campaign against the registry of the name cupuaçu as a trade mark at the Japanese Patent Office. The relevance of this case is due the way it reveals the logic and limits which drives stakeholders' actions in environmental conflicts, and its emphasis on TK's importance for development and innovation in Brazil. Additionally it analyses the increasing protagonism of organized civil society actors who promotes defensive actions towards TK. The theoretical framework is based within the Political Ecology approach, mainly its postcolonialist stream. The use of the contact zone concept allowed the analysis of different ways of knowing and owning TK and genetic resources, unveiling the creation, normalization and operacionalization of dominant concepts of knowledge and property within traditional knowledge "management". It was found that Brazilian institutional environment built to protect and promote TK acts as a "coordination island". In the context of cupuaçu case, it's emphasized also that traditional population's customary laws are excluded and subordinated to intellectual property instruments. The major difficulty identified by this article is that indebt granting of trade marks imputes to TK's holders the burden of proof and costs of claiming their rights. To halt biopiracy escalade and make it punishable, the need of its legal tipification as a crime is emphasized along with the support to traditional lifestyles and selected commercial partnerships. The regionalization of TK's "management" is highlighted in order to promote an interactive participation of traditional knowledge holders. This would allow a better evaluation of traditional knowledge specificities, improving global governance actions designed to its protection and promotion.

Key words: Traditional Knowledge; Sustainability; Cupuaçu; Biopiracy; Amazonlink.

\section{INTRODUÇÃO}

A discussão sobre propriedade intelectual (PI) e o patrimônio cognitivo-cultural dos povos indígenas e populações tradicionais é uma questão delicada, permeada por controvérsias, pois colidem interesses privados e públicos. Em virtude da especificidade do ativo em questão, há um limite bastante tênue que divide os direitos consuetudinários e morais das populações 
tradicionais, a propriedade intelectual e o interesse geral da sociedade. Instala-se, desse modo, um conflito atual e extremamente polarizado em torno da apropriação dos frutos do saber tradicional.

A partir de uma breve contextualização teórica do conceito de saber tradicional, populações tradicionais e propriedade intelectual, discutir-se-ão, neste artigo, os sentidos, usos e embates das diferentes formas de se conhecer e de se apropriar desses saberes e recursos associados. Isso será realizado com o auxílio do estudo de caso do cupuaçu, ${ }^{3}$ (Theobroma grandiflorum (Willd. ex Spreng.) K. Schum) que também considerará a atuação de ONGs locais, populações tradicionais e eventuais intermediadores na elaboração de uma agenda de governança ambiental global.

Com uma análise historicizada da PI, buscaremos entender suas origens, as diferentes justificativas para sua promoção em escala mundial, bem como os conflitos decorrentes de seu recente avanço sobre formas de conhecer até então intocadas pela mercantilização. De maneira complementar, analisaremos como os modos dominantes de se conhecer e se apropriar expressaram-se como técnicas de poder no debate da apropriação indébita do nome cupuaçu como marca comercial em países da Europa, América do Norte e Ásia. Examinaremos os grupos e as redes de poder que empregam os instrumentos de propriedade intelectual no sentido de criar privilégios e excluir os detentores do saber tradicional que fazem o uso desses saberes e recursos.

Com a realocação e apropriação indevida desses recursos no exterior, destacam-se os limites de controle do Estado brasileiro e a necessidade de novos instrumentos de gestão que viabilizem um sistema de governança ambiental global sui generis, mais adequado à especificidade dos saberes e recursos das populações tradicionais. Nesse sentido, buscar-se-á, neste artigo, interrogar e discutir o atual debate sobre a biopirataria não apenas como uma questão de acesso ao saber tradicional, mas principalmente como uma questão de justiça e equidade.

Escolheu-se o caso do cupuaçu não só porque este retrata emblematicamente a prática da biopirataria no Brasil hoje, 132 anos após o último embarque de sementes de seringueira para a Inglaterra, por Henry Wickham, mas também devido à maior aceitação dos seus envolvidos em participar da pequisa, bem como ao seu nível, mais completo, de desenvolvimento.

Além de ilustrar a dinâmica da biopirataria, o caso do cupuaçu permitirá um maior aprofundamento sobre a atuação de ONGs no sudoeste amazônico. Portanto, espera-se que, ao se analisar o conjunto de dificuldades práticas para se promover e proteger o saber tradicional naquela região, seja possível tanto revelar a atual redefinição do papel da PI nas lógicas de acumulação do capital, quanto contribuir para a discussão de instrumentos mais adequados para a gestão ambiental em nível global.

\section{AS POPULAÇÕES TRADICIONAIS E SEUS SABERES}

Antes de apresentar o debate acerca do saber tradicional, faz-se necessário qualificar e definir seus detentores, aqueles que baseiam sua subsistência, identidade, relações com os ecossistemas e modos de viver em formas de conhecimento essencialmente práticas, decorrentes não apenas da experiência cotidiana, mas também de uma herança cultural frequentemente renovada - as populações tradicionais e indígenas. Para Diegues (2000, p.18),

\footnotetext{
${ }^{3}$ Esse estudo de caso foi explorado na Tese de Doutorado Biopirataria ou bioprospecção: uma análise crítica da gestão do saber tradicional no Brasil, de Rezende, 2008.
} 
essas sociedades desenvolveram formas particulares de manejo dos recursos naturais que não visam diretamente ao lucro, mas à reprodução cultural e social como também percepções e representações em relação ao mundo natural, marcadas pela idéia da associação dessas populações com a natureza e da dependência de seus ciclos.

Neste trabalho, parte-se da noção de sociedades tradicionais como

grupos humanos culturalmente diferenciados que historicamente reproduzem seu modo de vida, de forma mais ou menos isolada, com base em modos de cooperação social e formas específicas de relacionamento com a natureza. Esta noção se refere tanto a povos indígenas quanto a segmentos da população nacional que desenvolveram modos particulares de existência, adaptados a nichos ecológicos específicos. (DIEGUES, 2000, p.22).

Cabe aqui também a ressalva de que o uso do termo tradição na definição dessas populações não busca restringir exclusivamente essa característica entre as comunidades estudadas, já que, a rigor, todas as culturas e sociedades possuem "tradição". Nesse sentido, citam-se como exemplos de populações tradicionais as comunidades caiçaras, quilombolas, sertanejos, ribeirinhos, caipiras, pescadores, caboclos, praieiros, povo de santo etc.

Mas afinal, o que é saber tradicional? Quais suas principais características e relevância? Porque é importante e como as diferentes abordagens teóricas informam as definições usadas pelos grupos de interesse envolvidos na sua gestão? Quais premissas e agendas estas definições revelam? Teria o conceito de saber tradicional se transformado em uma panacéia, uma nova moda entre as agências de desenvolvimento? Estaria ele sendo idealizado pelos movimentos sociais? Ou ele já teria morrido?

Até alguns anos atrás, no plano internacional, a discussão da criatividade intelectual das populações tradicionais era conduzida principalmente sob a denominação de folclore. Entretanto, devido às criticas que surgiram à época de que o termo era um arcaísmo que reproduzia uma visão eurocêntrica, na qual seriam consideradas apenas algumas manifestações culturais, e que não era capaz de englobar outros aspectos da herança cultural de populações tradicionais tais como o conhecimento é que foi cunhado o termo conhecimento tradicional. (BLAKENEY, 1999, p.2).

Atualmente, há uma profusão de definições e terminologias: conhecimento tradicional, conhecimento local, conhecimento indígena, conhecimento tradicional ecológico ou ambiental, entre outros. Como comentam Sillitoe e Bicker (2004, p.1), "qualquer que seja o termo empregado, existem objeções."

Em uma tipologia grosseira, à esquerda, junto aos movimentos sociais, e à direita, junto a algumas agências de desenvolvimento, o conceito de saber tradicional, em suas múltiplas faces, atingiu ambos os polos políticos: saber tradicional redescoberto, reinventado, deslocado, roubado, politizado, espiritualizado, exoticizado, mistificado, vitimizado, comercializado, desvalorizado, nacionalizado, localizado, etnicizado, desaparecido, perdido e até assassinado.

Nesse quadro de modismo intelectual, existe muito oportunismo na maré alta do saber tradicional. Não há dúvida de que a apropriação conceitual entre disciplinas acadêmicas é uma prática potencialmente fértil. Essa, porém, não tem sido a prática, principalmente no contexto de apropriação desse conceito pelas agências de promoção do desenvolvimento e movimentos sociais. 
Isso acabou por reproduzir uma série de preconceitos e até confusões às quais antropólogos e outros cientistas sociais já trabalharam para sanar. Mais do que isso, algumas dessas reinterpretações enganosas do saber tradicional têm sido vistas até com uma vantagem para seus defensores, como é o caso da reedição do mito do bom selvagem em seu suposto aspecto de "conservacionista nato". (KRECH, 2000). Ao contrário de uma comunhão, proximidade ou união mística com a natureza, o convívio desses povos com a natureza tem pouco a ver com a imagem rousseauniana do "bom selvagem", desenvolvida a partir de uma leitura específica da literatura de viagens. (FRANCO, 1976).

De acordo com Ellen, a persistência do mito da sabedoria ambiental primitiva dever-se-ia às seguintes razões: em primeiro lugar, porque algumas sociedades particulares possuem, de fato, ideologias e cosmologias que enfatizam a harmonia ambiental; em segundo lugar, porque em diversos momentos antropólogos e outros pesquisadores descreveram o que pareciam ser sociedades que possuem uma economia ecologicamente autossustentável. Em terceiro lugar, porque muitos julgaram oportuno usar o conceito darwiniano de "adaptação" para explicar por que essas sociedades alcançaram esta acomodação favorável. (ELLEN e HARRIS, 2000).

Geralmente, ao tratar o meio que os cercavam com o mesmo respeito com que tratariam seus próprios antepassados, esses povos desenvolveram sistemas de conhecimento mais integrados ao meio ambiente, de modo que o sagrado e o secular tornam-se inseparáveis. Assim, pode-se afirmar que esses saberes dependem não somente da relação entre seres humanos e natureza, mas também da relação entre o mundo visível e o invisível, espiritual.

Em decorrência dessa visão de mundo, na qual tudo estaria conectado, Posey (1999) chamou essa imbricação de valores culturais/espirituais com o meio ambiente de "elo inextrincável”. Para este autor, é a partir dessa interface que se originariam as práticas sustentáveis dessas populações, condicionando os chamados “estilos de vida tradicionais”, que, remarcados pelo padrão dinâmico e sustentável de uso de recursos em seu território, poderiam ser expressos pelas populações tradicionais através dos seguintes valores:

- Cooperação;

- Laços familiares e comunicação entre gerações, inclusive com os antepassados;

- Preocupação com o bem-estar das gerações futuras;

- Autos-suficiência em escala local e dependência dos recursos naturais disponíveis localmente;

- Direitos às terras, territórios e recursos que tendem a ser coletivos, em vez de individuais e alienáveis;

- Restrições na exploração de recursos e respeito à natureza, especialmente pelos lugares sagrados. (POSEY, 1999, p.4).

Além desses valores, pode-se acrescentar às demais características do conhecimento tradicional a questão da oralidade da sua transmissão, já que a grande maioria das populações não possui uma tradição escrita de repasse desse saber.

Assim, levando-se em conta os aspectos relativos à visão de mundo preponderante entre as populações tradicionais e os valores que dirigem seus estilos de vida, podem-se elencar, resumidamente, as seguintes características da dinâmica do saber tradicional:

- Mantido e produzido coletivamente;

- Transmitido oralmente de geração para geração;

- Dinâmico, evolui com o tempo; 
- Acesso e uso do saber tradicional dessas populações geralmente é governado por uma ampla variedade de leis usuais não-escritas e comumente aceitas.

Também é importante ressaltar que o território dessas comunidades é muito mais que um simples espaço geográfico de reprodução econômica, mas também o locus das relações sociais, das representações do imaginário mitológico e religioso que guiam o saber e o saber fazer dessas populações sobre o meio físico que habitam, ou seja, o espaço físico pode ser considerado como parte integrante dessas populações. (BERKES et al., 2000, p. 1252).

Em resumo, poderíamos elencar as seguintes características-chave do saber tradicional: sua ancestralidade, adaptabilidade, autenticidade, transmissão oral ou não escrita, distribuição desigual na população, especificidade contextual, informalidade e seu aspecto tácito.

Após essa breve discussão sobre as definições de saber tradicional e seus detentores, caberá ao próximo tópico discutir sua realocação e aplicação comercial, no contexto da economia informacional, através de instrumentos de PI.

3

\section{O SABER TRADICIONAL NO CONTEXTO DA ECONOMIA INFORMACIONAL}

Uma compreensão inicial da atual aceleração na busca pelo saber tradicional, ou "corrida" pelo conhecimento tradicional, pode ser obtida ao se responder às perguntas: Quem visita as populações tradicionais? $\mathrm{O}$ que se procura? Por quê? $\mathrm{O}$ que acontece com o conhecimento tradicional nas populações tradicionais e na sociedade envolvente? Quem se beneficia do conhecimento tradicional? (REZENDE, 2008).

Esse objetivo será buscado aqui ao se esclarecer como essa "corrida" vem se manifestando na prática, no cotidiano das populações tradicionais e, em segundo lugar, ao se reunir argumentos que permitam atestar que a atual aceleração na dinâmica social e espacial da coleta de recursos genéticos e saberes associados é fruto de uma nova e contemporânea combinação de fatores econômicos, tecnológicos e regulatórios.

De maneira geral, as pessoas que visitam as populações tradicionais podem ser desde turistas até extratores; no entanto, nem todas as pessoas que visitam essas comunidades são malintencionadas. Por mais óbvio que isso possa parecer, relevar isso também importa para entender que, às vezes, mesmo sem intenções escusas, os visitantes podem ignorar os impactos negativos de suas atividades (POSEY e DUTFIELD, 1996, p.11).

Os interesses que dirigem essas visitas são os mais variados, desde lazer, no caso de turistas, ou uma reportagem interessante, para jornalistas, até a conversão religiosa das pessoas da comunidade, no caso de alguns missionários. Já o interesse voltado para o saber tradicional dessas populações, que pode ser tanto com fins comerciais ou não, geralmente está voltado para o desenvolvimento de pesquisas científicas na área agrícola, botânica, arqueológica, antropológica e das etnociências de modo geral. Nas visitas de pesquisadores diretamente voltados para aplicação comercial do conhecimento tradicional pelas indústrias, busca-se geralmente:

- Conhecimento do uso atual, prévio, ou potencial tanto de espécies de plantas e animais, como de minerais e outros componentes do solo;

- Conhecimento das formas de preparação, processamento ou armazenamento de espécies úteis;

- Conhecimento de formulações envolvendo mais de um ingrediente; 
- Conhecimento de espécies individuais (localização, identificação, métodos de cultivo, critérios de seleção etc.);

- Conhecimento de conservação do ecossistema (métodos de proteção ou preservação de um recurso que tenha valor comercial) e

- Sistemas de classificação do conhecimento tradicional, tal como a classificação sistemática tradicional. (POSEY e DUTFIELD, 1996, p.36).

Esses tipos de conhecimento descritos acima seriam procurados pelas empresas multinacionais como insumo para o desenvolvimento de novos produtos, servindo como "atalho" ou "filtro" que confere uma maior eficiência no processo de desenvolvimento de inovações tecnológicas.

A importância do conhecimento tradicional para a consecução dessas inovações no setor farmacêutico é corroborada por Farnsworth (1997), quando este relata que mais de $80 \%$ dos fármacos com algum princípio ativo derivado de plantas comercializadas atualmente têm correlação positiva entre a sua aplicação na medicina tradicional e a sua indicação terapêutica pelos médicos.

Para Leonel (2000, p. 333), "três quartos das drogas utilizadas pelo receituário médico derivam de plantas descobertas do conhecimento indígena. De 120 componentes ativos isolados de plantas, $75 \%$ têm origem em seu uso tradicional."

De modo complementar, também é possível inferir, através de dados de Elisabetsky (2000, p. 95), que as chances de se encontrar um composto ativo numa planta rastreada a partir de uma informação etnobotânica são mais de mil vezes maiores do que as chances das técnicas de rastreamento randômicas convencionais.

Além dos fatores descritos acima, que acentuam a importância do saber tradicional para indústrias dos setores farmacêutico, alimentício, cosmético, agrícola e nutracêutico, é importante ressaltar algumas características do sistema de propriedade intelectual e seu papel na atual economia informacional para obtermos um quadro mais completo da aplicação desses saberes na atualidade.

Para isso, buscar-se-á situar em seguida o atual momento da economia capitalista através do conceito de economia do aprendizado assim como trabalhado por Lundvall (1994). A premissa subjacente a essa perspectiva é de que a economia atual tem no conhecimento seu recurso mais estratégico; afinal, ele é imprescindível à realização do processo produtivo e de fundamental importância para a determinação do grau de produtividade, seja este físico ou em valor monetário. (LUNDVALL,1994; POSSAS, 1999).

Desse modo, nesse novo contexto, o conhecimento é transformado em uma mercadoria que as firmas tentam capturar, gerando conflito entre o acesso a esse conhecimento que é produzido socialmente e a sua apropriação através dos direitos de propriedade intelectual por parte das organizações privadas. (JOHNSON e LUNDVALL, 2000, p.2).

No entanto, diferentemente dos demais fatores de produção, o conhecimento não é facilmente transacionável no mercado. Arrow (1962) analisou as dificuldades de se criar um mercado para a informação a partir de sua natureza indivisível, seu caráter não rival, e do fato de que o comprador não poder avaliar seu valor antes de possuí-la. Mas o que realmente caracterizaria esse novo padrão de acumulação em que vivemos?

Rifkin (1999) salienta que estaríamos vivendo uma dramática e histórica revolução, em que a fusão dos computadores e dos genes estaria possibilitando um novo ciclo de acumulação 
capitalista. A tecnologia da informação forneceria a linguagem, a ferramenta para decifrar, organizar e gerenciar a informação genética, enquanto que estes últimos seriam o recurso bruto deste século, assim como o petróleo e metais foram no século passado.

Para Castells (1989), a característica mais marcante dessa verdadeira revolução informacional não seria apenas a centralidade da informação ou o desenvolvimento de tecnologias, que possibilita e otimiza a sua transmissão, mas sim "a criação de tecnologias capazes de reprocessar criativamente essa informação, recombinando-a ou replicando-a, de maneira a adicionar-lhe valor”. (p.12).

É interessante notar que as mudanças nos modos de se apresentar e representar o conhecimento tradicional também facilitou a sua concentração e arquivamento. A informação que era guardada pelas pessoas agora pode ser representada e armazenada em arquivos de computador, em grandes quantidades. Isso facilitou muito a coleção e o acesso recorrente a estes conhecimentos, ainda que seu conteúdo sofra alterações ou corrupções de alguns de seus elementos durante o processo.

É nesse sentido que se acredita que a concepção de economia informacional, reunida às características do saber tradicional, apresentadas anteriormente, permite uma compreensão mais completa das novas práticas de sua transferência e circulação, principalmente ao enfatizar o modo como essas técnicas tornaram mais fáceis e eficientes a coleta, a transmissão e o armazenamento, a concentração, a recombinação e a recirculação desses materiais e conhecimentos.

A indústria foi rápida e eficiente em configurar o marco legal responsável pela regulamentação do uso econômico dos recursos genéticos e do saber tradicional. Essa visão é corroborada por outros autores, como Scholz (2003), Parry (2004) e Seini (2003). Para Scholz (2003, p. 214),

As mudanças tecnológicas sofridas pela indústria biotecnológica nos últimos dez anos influenciaram a distribuição de poder global nas negociações sobre a biodiversidade, introduzindo essa indústria como um ator-chave na arena das negociações políticas internacionais do meio ambiente.

Essas mudanças tecnológicas que repercutiram no setor da biotecnologia, a partir dos anos 1970, alimentaram um aumento da demanda por recursos biológicos e saber tradicional. Apesar disso, ainda não existiam regulamentações formais acerca da transferência e uso desses recursos.

Mas afinal, como os atuais sistemas regulatórios, particularmente sistemas de propriedade intelectual, têm atuado na criação de um novo mercado de saber tradicional? Seguimos, discutindo os efeitos do avanço irrestrito do sistema de propriedade intelectual, com o intuito de investigar como eles têm operado para a constituição do saber tradicional como uma mercadoria autônoma, determinando as novas condições de seu uso e troca.

\section{PROPRIEDADE INTELECTUAL: DINÂMICA E LIMITES DE APLICAÇÃO PARA PROTEÇÃO DO SABER TRADICIONAL}

A propriedade intelectual não é apenas um fenômeno que articula a produção do conhecimento com a formação do capital em um plano estritamente econômico ou técnico, ou uma mera imposição advinda da escassez da informação (SÁDABA, 2008). Para ampliar o atual escopo das análises sobre PI, ainda restritas a abordagens jurídico-legalistas, de economia neoclássica ou historiografia da ciência e tecnologia com viés eurocêntrico, faz-se necessário buscar, em profundidade, as mudanças sociais, institucionais, ideológicas e culturais que 
embasam a PI, afinal esse fenômeno altera substancialmente os direitos das populações tradicionais a manter e promover seus conhecimentos, e dos cidadãos em geral ao acesso à cultura, à ciência, à saúde, e até mesmo à vida.

Essa visão é corroborada por Gandelman (2004, p. 96) que entende

que o processo de formação de um regime internacional (de propriedade intelectual) tem sido tratado como um assunto que diz respeito exclusivamente ao campo do direito, ou como um tema que tem alguma relação, no máximo, com certas questões econômicas. Mas jamais ele é entendido como resultado de relações de poder geradas pela estrutura do sistema internacional; e muito menos como tema de economia política internacional.

A ubiquidade da PI hoje é clara e inelutável. Com a sua extensão a novas esferas da vida, através da extensão do processo de mercantilização, redefinem-se o papel da ciência e da tecnologia, os modos de produção e inovação, assim como as suas formas de regulação legal.

Para muitos observadores, a recente proliferação de pedidos de propriedade intelectual no começo deste século, protagonizada pela ascensão da economia informacional, pode ser vista como parte de um processo maior de "novo cercamento dos comuns" ou ainda uma "grilagem intelectual em massa" em que recursos que eram tidos como bens públicos passam a ter seu acesso restrito e acabam por se transformar em mercadorias escassas. (AOKI, 1996; BOYLE, 1996; apud HUMPHREY e VERDERY, 2004).

Nesse sentido, é importante remarcar que a propriedade intelectual é uma instituição que tem seu dinamismo ditado pelos interesses dos proprietários das corporações que se inserem em campos tecnológicos emergentes que não possuam ainda mecanismos de proteção institucionalizados - ou seja, de acordo com o surgimento e desenvolvimento de novos produtos e processos, cuja proteção ainda não seja contemplada no sistema vigente, vide caso atual da biotecnologia, em que seus representantes logo se apressam em criar mecanismos de proteção adequados às especificidades do novo negócio. Comumente, ela é apresentada como um sistema de disposições jurídicas que autorga direitos temporais sobre bens supostamente derivados da atividade criativa ou inventiva.

As leis que regulamentam a propriedade intelectual tentam proteger os criadores e outros produtores de mercadorias e serviços intelectuais através da concessão de certos direitos temporários para controlar o uso a ser feito desses produtos. Assim, a propriedade intelectual provê direitos relacionados a: i) trabalhos literários, artísticos e científicos; ii) apresentações artísticas e transmissões de programas pela mídia; iii) invenções em todos os campos de atividade; iv) descobertas científicas; v) desenho industrial; vi) marcas, designações e nomes comerciais e vii) proteção contra práticas desleais de competição (OMPI, 2001).

Já a justificativa hegemônica de seu emprego decorreria da conciliação de dois objetivos contraditórios. Primeiro, a publicação das ideias, invenções e criações, de modo a torná-las disponíveis a terceiros que poderiam posteriormente incrementá-las, nutrindo, assim, o desenvolvimento técnico e a inspiração artística. Segundo, o incentivo econômico para as pessoas que estão envolvidas em esforços criativos, de modo que os criadores possam captar os retornos financeiros decorrentes desse emprego (ASEAN, 2000, p. 6).

Nesse contexto, os paladinos da difusão dos instrumentos de propriedade intelectual para promoção do desenvolvimento alinham, de modo geral, as seguintes consequências propiciadoras de desenvolvimento - advindas da aplicação do sistema: (i) agregação de valor; (ii) conquista de novos nichos de mercado; (iii) maiores investimentos em pesquisa e desenvolvimento; (iv) fonte de informação tecnológica e (v) aumento dos investimentos diretos 
estrangeiros. Essas seriam as características favoráveis à promoção de inovações tecnológicas e, portanto, ao desenvolvimento. De um modo geral, essa abordagem economicista parte de uma premissa gradualista e reducionista do desenvolvimento, em que a "proteção à inovação" - leiase fortalecimento irrestrito das leis de propriedade intelectual - "atuaria como fermento do desenvolvimento econômico dos países” (SHERWOOD, 1992, p.16).

Mas será que as inovações tecnológicas, e a criatividade de modo geral, dependem da propriedade para sua continuidade? Será que na ausência desse regime o desenvolvimento tecnológico e científico ficaria reprimido? E o saber tradicional? Desapareceria nesse quadro? Responder a essas perguntas é de fundamental importância uma vez que tratar a criatividade humana do mesmo modo que outra mercadoria qualquer traz implicações importantes para sua proteção e incentivo em contextos culturais diferenciados, podendo ocasionar a erosão ou até mesmo a perda daqueles saberes sem valor de troca mercantil.

Longe de "satanizar" o sistema de propriedade intelectual e, mesmo considerando-o como um ativo complementar fundamental para garantir a apropriação e agregação de valor em um ambiente de concorrência, cabe lembrar que seu uso adequado para os fins da inovação tecnológica requer, antes, uma análise detalhada do estágio de desenvolvimento dos setores industriais a serem afetados no país em questão e no exterior. Ou seja, para ter a cabo seus efeitos positivos para a promoção do desenvolvimento, seu emprego deve ocorrer como um elemento componente de um grupo de ações de política industrial, integradas e orquestradas seletivamente em um sistema nacional de inovação.

Recentemente, vários autores (DUPAS, 2007; CORREA, 2007 e DAVID, 2006) vêm criticando o desvirtuamento do sistema de PI, que estaria deixando de atender e proteger o interesse da sociedade como um todo, como um mecanismo de promoção da inovação, para se tornar um instrumento utilizado pelas corporações na esfera da concorrência.

Para David, “o regime de patentes adquiriu uma vida própria independente do propósito original do sistema, a saber, o incentivo à invenção e a revelação pública de produtos e meios de produção novos e úteis.”

A idéia toda do sistema de patentes como um sistema de informação é terrivelmente importante porque sua implementação provê recursos de informação para os inventores individuais e alimenta um processo cumulativo de feedback, gerando sistemas tecnológicos novos através da recombinação dos elementos constituintes disponíveis. Mas ele não é tão completamente explorado quanto deveria ser. (ibidem, 2006, p.117)

Essa visão é corroborada por Correa (2007), para quem existiria uma

proliferação de patentes obtidas como parte de estratégias sofisticadas para defender avanços tecnológicos ou bloquear a inovação ou competição direta de terceiros. É preciso repensar seriamente o atual sistema de patentes e até que ponto ele pode alcançar ou não seu objetivo tencionado (promover a invenção para o benefício da humanidade).

Portanto, ao invés de se buscar uma expansão irrestrita do sistema, como ditam a Organização Mundial da Propriedade Intelectual (OMPI) e a Organização Mundial do Comércio (OMC), há hoje um crescente consenso sobre a necessidade de reformular o sistema de patentes internacional como uma ferramenta para recompensar invenções genuínas, e também preservar o espaço de competição legítima, promover inovações e aumentar a difusão tecnológica, particularmente em países em desenvolvimento. 
Em adição, esse sistema deveria estar baseado também em condições de equidade, e ser flexível o bastante para responder às necessidades daqueles que não podem pagar os preços maiores associados à concessão de direitos exclusivos (CORREA, 2007 e COMISSÃO BRITÂNICA SOBRE DIREITOS DE PROPRIEDADE INTELECTUAL, 2002).

A questão da aplicação da propriedade intelectual à biodiversidade e aos saberes tradicionais é ainda mais conflitante. Segundo Santos (1997, p. 89),

os direitos de propriedade intelectual protegem o conhecimento tecno-científico moderno e a possibilidade de converter as inovações biotecnológicas em fonte de imensos lucros. Por isso mesmo, os Estados Unidos e os países industrializados preconizam a universalização desses direitos, tanto em nível internacional (via GATT-TRIPs, OMC, CBD, Banco Mundial e outras instâncias multilaterais), quanto em nível nacional (via adoção do regime de patentes e de leis de cultivares pelo maior número possível de países).

Como se procurou argumentar na seção anterior o saber tradicional possui um caráter originalmente coletivo, portanto sua dimensão cooperativa e natureza irremediavelmente social não se adequariam aos preceitos e condições de patenteabilidade. Apesar de existirem pessoaschave nas comunidades que acumulam esse saber, não existe a figura mitológica do inventor heróico, que irrompe, com sua torrente de criatividade, empreendimentos inovadores cuja difusão poderia beneficiar toda a comunidade através do monopólio temporal da comercialização de sua inovação.

Além do "inventor" do saber tradicional não ser individualizado, o caráter temporal da proteção conferida pelos instrumentos de PI é um problema quando se consideram os efeitos da mercantilização sobre a sua herança cultural.

Longe de se configurar em uma ameaça para reprodução social de suas gerações futuras, a mercantilização irrestrita pode ocasionar até o desaparecimento desses saberes, uma vez que, com a destruição dos modos de vida tradicionais e a burocratização da atividade inventiva ameaça-se interromper a criatividade dessas populações, em um verdadeiro choque de sistemas de conhecimento e apropriação.

De modo complementar, ao analisar as inadequações da aplicação do sistema de propriedade intelectual para a proteção do conhecimento tradicional, Posey (1999, p.12) modificado pelos autores deste artigo- sintetiza algumas causas:

- A propriedade intelectual reconhece direitos individuais, e não coletivos;

- Requere um ato específico de "invenção";

- Requere a existência de aplicação industrial (patentes)

- Simplifica os regimes de propriedade;

- Estimula a comercialização;

- Reconhece somente valores para o mercado;

- É sujeita aos atores com maior poder econômico e sua manipulação;

- São difíceis de monitorar e de ter seu cumprimento assegurado;

- São caros, complicados e demorados.

A dificuldade de se encaixar essa forma de produção coletiva no mercado ilustra a dificuldade insuperável de se proteger e promover - e inclusive valorar, quando for o caso - o saber tradicional através da PI. Como corolário, o uso da PI implicaria também que todos aqueles 
saberes sem aplicação comercial direta estariam fadados ao desaparecimento, dado seu baixo grau de instrumentalidade.

Portanto, com o desenvolvimento de marcos jurídicos transnacionais e amplos, ocorre o desprendimento de bens culturais e técnicos nacionais para o seu envolvimento em um vasto espaço de práticas globalizadas de pesquisa e desenvolvimento, e inovações tecnológicas. Como novos insumos ou fatores de produção, os saberes tradicionais passam a integrar o ciclo da economia global através de mecanismos de PI, com sérias conseqüências para seus detentores.

Espera-se um maior aprofundamento nessa questão a partir do estudo de caso, tratado a seguir.

\section{O CASO DO CUPUAÇU}

O cupuaçuzeiro (Theobroma grandiflorum, Schum) é uma árvore frutífera encontrada em estado silvestre nas matas da parte sul e sudeste da Amazônia Oriental. Entretanto, seu uso e cultivo disseminam-se por toda a bacia Amazônica, e é uma das frutas mais atrativas da região, principalmente devido às excelentes características de aroma e sabor de sua polpa. (RIBEIRO, 1992).

O nome cupuaçu é de origem tupi, e significa em português "fruto grande”. Com a sua polpa, que pode ser retirada tanto mecanicamente quanto manualmente, preparam-se sucos, sorvetes, doces, licores, cremes, geléias, biscoitos, iogurtes, bombons etc.

A análise do valor nutricional dessa polpa revela excelentes características e teores médios de fósforo e de vitamina C (CALZAVARA et al., 1984, apud FRAIFE FILHO, 2000, p.2). Já da sua semente obtém-se a matéria-prima para produção do "cupulate", um produto semelhante ao chocolate, cuja produção comercial já foi viabilizada experimentalmente pela estação da Empresa Brasileira de Pesquisa Agropecuária (EMBRAPA) em Belém - PA, além da produção de gordura, que é utilizada principalmente como insumo por indústrias de cosméticos.

Apesar de ter sua produção e consumo concentrados na região Norte do Brasil, a cultura do cupuaçuzeiro vem se expandindo, e atualmente atinge até algumas áreas no estado de São Paulo. No estado da Bahia, a área plantada é de aproximadamente 254 hectares, localiza-se principalmente no sul do Estado, e fornece uma produção de cerca de 200 toneladas de polpa/ano e produtividade média de 30 a 40 frutos/planta/ano. Entretanto, deve-se ressaltar que a produção do cupuaçuzeiro no Brasil concentra-se na região Amazônica, sendo o estado do Pará o principal produtor, seguido do Amazonas, Rondônia e Acre (LOPES, et al. 1999 e FRAIFE FILHO, 2000).

Dados primários desta pesquisa, apontam que em Rio Branco - AC, nas feiras livres e mercados de pequenos produtores, os frutos comercializados alcançam preços que variam de $\mathrm{R} \$ 1,00$ até $\mathrm{R} \$ 1,50$ por unidade. O litro da polpa congelada - principal forma de comercialização do cupuaçu - pode ser encontrado a preços que variam de $\mathrm{R} \$ 3,00$ a $\mathrm{R} \$ 3,50$ ao produtor, e o preço dos bombons de cupuaçu varia entre $\mathrm{R} \$ 0,50$ e $\mathrm{R} \$ 1,50$ no comércio varejista de Rio Branco. (REZENDE, 2008).

A partir da grande multiplicidade de usos, produtividade, e das características organolépticas desejáveis do fruto e seus derivados, a produção comercial do cupuaçu vem alcançando destaque como uma das fruteiras com maior potencial econômico na Amazônia, visto que as indústrias nacionais e estrangeiras já manifestam interesse em adquirir grande volume de polpa e semente, enquanto que algumas inclusive já lançaram produtos derivados de cupuaçu no mercado (RIBEIRO, 1992). 
Um desses produtos é inclusive protagonista principal no caso a ser estudado - o bombom de cupuaçu. Esse caso inicia-se por ocasião da tentativa da ONG acreana AMAZONLINK em comercializar o bombom de cupuaçu no mercado alemão, no final de 2002.

A AMAZONLINK tem sede em Rio Branco, foi fundada em setembro de 2001 e tem como objetivo declarado superar fronteiras políticas, culturais, ideológicas e de língua em prol da colaboração na preservação da Amazônia e no melhoramento das condições de vida de seus habitantes. Na consecução desse objetivo, a ONG busca disponibilizar informações socioambientais na internet, promover o estudo, pesquisa e divulgação das causas dos problemas ambientais e sociais da Amazônia e das possíveis soluções visando o desenvolvimento sustentável, a promoção da cidadania, dos direitos humanos, da democracia da assistência social às minorias e excluídos, dos direitos da mulher e da criança, assessoria jurídica gratuita, assim como combate à pobreza e a todo o tipo de discriminação sexual, racial e social, trabalho forçado e infantil, entre outras ações.

Desde sua fundação, a AMAZONLINK atua promovendo o comércio de artesanato indígena junto a seus contatos internacionais via rede de mercado solidário fair trade. A partir do interesse de contatos dessa rede por bombons de cupuaçu, a AMAZONLINK enviou amostras para análise do potencial comercial do produto na Europa.

O contato em questão foi a ONG alemã Regenwald Institute, que, após receber uma amostra de bombons de cupuaçu, procedeu um levantamento no escritório europeu de propriedade intelectual para verificar a existência de registros prévios de propriedade intelectual.

Apesar de os representantes da Regenwald Institute terem gostado muito do produto, eles solicitaram à AMAZONLINK que retirassem o nome cupuaçu do rótulo, alegando que era uma marca da empresa japonesa ASAHI FOODS. Com essa notícia, houve uma reação de espanto na AMAZONLINK, o que ensejou uma solicitação de confirmação da concessão da marca.

Após a confirmação da solicitação da marca comercial nos escritórios de patente dos EUA, Japão e Europa, verificou-se também a existência de patentes sobre o processo de obtenção do "cupulate" - tipo de doce, similar ao chocolate, preparado a partir da semente do cupuaçu - e também sobre o processo de obtenção do óleo. Na questão específica do registro de marca comercial, verificou-se que, para efetivar-se a exportação de cada lote de bombons, deveriam ser pagos 10 mil dólares norte-americanos, a título de royalties, para a empresa, independente do tamanho da remessa.

Esse fato revela um mecanismo perverso da propriedade intelectual, pois, nos termos estritos da sua própria regulamentação, o registro das marcas comerciais pelos escritórios de PI deve contemplar o critério de distinguibilidade. Segundo esse princípio, o nome do produto não pode ser usado como marca comercial, ou seja, de acordo com a própria legislação de PI, o nome cupuaçu não pode ser registrado como marca comercial de um produto que contém cupuaçu.

Nesse sentido, o caso do cupuaçu exemplifica claramente as práticas condescendentes dos escritórios de propriedade intelectual, principalmente entre os países do Norte, pois uma simples busca do nome cupuaçu na internet revelaria que não se trata de um nome novo, mas sim do nome exato de um fruto com amplo uso no Brasil, ferindo um dos principais critérios para a concessão da marca comercial.

Afinal a marca é um tipo de sinal distintivo, assim como as indicações geográficas, que são constituídas para tentar evitar a concorrência desleal, baseando-se no argumento de que é injusto apresentar um produto a uma pessoa como sendo de outra (SHERWOOD, 1992, p. 27). Geralmente, as marcas apresentam-se como uma palavra ou sinal que serve para identificar com exclusividade e distinguibilidade da fonte de um produto ou serviço. Quanto a essa forma de 
apresentação, a marca pode ser nominativa, figurativa, mista ou tridimensional. Cabe ainda acrescentar que seu registro e gestão no Brasil são coordenados pela Lei 9.279, de 14 de maio de 1996, assim como as patentes e as indicações geográficas e os crimes de concorrência desleal.

Pode-se afirmar que o registro da marca cupuaçu pela empresa japonesa visou, na verdade, a criação de um direito ilegítimo, viabilizado por procedimentos lenientes dos escritórios de PI, que não raro, falham ao verificar os critérios de distinguibilidade e novidade, fundamentais na análise e concessão de marcas comerciais.

Também cabe ressaltar que no atual procedimento de concessão de marcas dos escritórios de PI, não se faz nenhuma pesquisa prévia, inicialmente o escritório apenas autua o pedido, e não havendo contestações em determinado período de tempo, concede-se o registro da marca. No caso específico, o pedido do registro era de 1998, e como o prazo para as contestações era de 5 anos, restava portanto menos de um ano para a organização e realização de uma ação contestatória da marca.

No entanto, acredita-se que a maior perversidade do uso da propriedade intelectual como mecanismo defensivo pela empresa japonesa ASAHI FOODS, no sentido de se ampliar e garantir antecipadamente a apropriação do nome cupuaçu, é que ele imputou aos detentores originais e seus aliados o ônus da contestação da marca reclamada indevidamente pela empresa.

Ou seja, no atual modo de operação do sistema de propriedade intelectual, cabe aos detentores do saber tradicional e recursos biológicos honrarem com os honorários advocatícios necessários para contestar as marcas reclamadas e concedidas indevidamente nos escritórios de PI. Em um segundo momento, os membros da AMAZONLINK tentaram obter apoio junto ao Estado brasileiro no sentido de contrapor esse pedido de registro da marca cupuaçu, uma vez que este ainda não havia sido concedido no exterior.

Mesmo com o relato do caso do cupuaçu e do grande número de patentes e marcas concedidas indevidamente no exterior, a reação dos órgãos estatais consultados pela ONG foi desestimuladora. Agências estatais consultadas como o INPI (Instituto Nacional de Propriedade Intelectual) preferiram ignorar o fato, alegando que isso era relativamente comum no sistema de propriedade intelectual.

Além do desestímulo à iniciativa da ONG em contestar o pedido indevido do registro de marca pela empresa ASAHI FOODS, aponta o desaparelhamento do Estado brasileiro para se coibir e reprimir ações de biopirataria.

A reação da ONG frente essa situação foi elaborar um dossiê sobre a concessão de patentes indevidas a partir de recursos genéticos brasileiros, que foi divulgado junto à imprensa local e logo ganhou grande destaque nacional. Foi somente a partir da repercussão nacional do caso é que o Estado atuou de modo mais efetivo.

Inclusive pode-se observar, em entrevistas realizadas por Rezende (2008), que o MRE (Ministério das Relações Exteriores) teve uma ação importante tanto em um primeiro momento, quando buscou convencer a empresa ASAHI FOODS em desistir do pedido de registro da marca, quanto no encaminhamento formal do pedido de anulação do pedido nos escritórios europeu e norte-americano de PI.

No mesmo trabalho, também foi relatado, que alguns funcionários do MRE, ao reclamarem consternados da falta da verba para empreender uma ação legal internacional contra esse pedido de marca, chegaram a interrogar alguns componentes da ONG acerca da possibilidade da mesma financiar algumas passagens aéreas.

Diante desse quadro, e com a ampla repercussão do caso na mídia, a ONG optou por solicitar apoio financeiro junto a outras organizações não-governamentais nacionais e internacionais, no 
sentido de se financiar uma ação contestatória do pedido da marca no escritório japonês de propriedade intelectual. Isso foi realizado a partir de uma parceria entre a AMAZONLINK, a Rede GTA (Grupo de Trabalho Amazônico), o GREENPEACE, entre outras, e originou a campanha "Limites éticos acerca do registro de marcas e patentes de recursos biológicos e conhecimentos tradicionais da Amazônia”, Essa campanha ficou mais conhecida pelo seu bordão: “O cupuaçu é nosso!”, que além de aludir à campanha pela nacionalização da extração do petróleo brasileiro, ocorrida no início do século passado, inspirou também o título deste trabalho.

Esta campanha foi viabilizada a partir da doação anônima de um inglês, que deu um cheque de 8 mil libras esterlinas para o GREENPEACE em Londres. Com esse valor, a AMAZONLINK produziu vídeos, panfletos informativos e o sítio www.biopirataria.org.. Ainda nessa fase, começaram os estudos para a implementação do Projeto Aldeias Vigilantes, que viria a se tornar, posteriormente, um dos principais desdobramentos práticos do caso.

A campanha “O cupuaçu é nosso!" levantou, ainda, informações sobre pedidos de patentes e marcas feitos a partir de recursos genéticos e saberes tradicionais, e organizou atos públicos de repúdio à biopirataria no Acre. Também mobilizou várias ONGs como o IDCID (Instituto de Direito do Comércio Internacional e Desenvolvimento), que procedeu a um levantamento dos instrumentos jurídicos cabíveis ao questionamento do pedido de registro da marca, e a Associação de Produtores Alternativos de Rondônia (APAFLORA), que atuou na mobilização social local.

Uma vez tendo-se formulado a estratégia de ação, que focou, em primeiro lugar, na tentativa de impugnação das solicitações dos registros das marcas cupuaçu e cupulate no Japão, o escritório Trench, Rossi e Watanabe - com sede em São Paulo, SP - assumiu as despesas dos serviços de advocacia.

Em seguida, o processo foi aberto por AMAZONLINK, GTA, APAFLORA e IDCID. A linha de argumentação defendida alegou que, pela própria regulamentação da propriedade intelectual, o nome de uma matéria-prima não pode ser o mesmo nome da marca, ou seja, se o produto que a ASAHI FOODS gostaria de proteger contém cupuaçu, a empresa não pode registrar esse nome como marca comercial.

Como suporte à argumentação levantou-se uma ampla literatura sobre o cupuaçu, atestando desde a origem do nome junto aos indígenas do macro-tronco linguístico Tupi, até a atual difusão do seu cultivo e uso no Brasil.

Um ano após a instrução do processo, o escritório de propriedade intelectual japonês acolheu a demanda do grupo brasileiro de ONGs e decidiu negar o pedido de registro da marca cupuaçu à empresa ASAHI FOODS.

Também em decorrência desse processo, e antes mesmo da queda do pedido de registro da marca cupuaçu no escritório de PI japonês, em março de 2004, houve o cancelamento do pedido de patente sobre o processo de produção de óleo e gordura do cupuaçu, em fevereiro de 2004.

Em seguida, o MRE passou a encaminhar pedidos de anulação similares junto aos escritórios de PI norte-americano e europeu. No entanto, em janeiro de 2005, a própria empresa desistiu da solicitação do registro nos EUA e, em fevereiro desse mesmo ano, veio a desistir do registro da marca cupuaçu no escritório europeu.

A partir da análise do caso do cupuaçu, pode-se destacar que a contestação do pedido de registro da marca não se baseou em acordos internacionais, como a Convenção sobre a Diversidade Biológica (CDB), que também podem ser usados para proteger o saber tradicional; pelo contrário, partiu de dentro do próprio marco da propriedade intelectual. Isso revela a precariedade deste acordo internacional no sentido de coibir abusos advindos da aplicação das ferramentas de propriedade intelectual sobre os recursos genéticos e saberes associados. 
Deve-se ressaltar também que a contestação e a queda do pedido de registro da marca do cupuaçu pela empresa ASAHI FOODS não impedem que sejam feitos novos pedidos do registro desse nome como marca comercial, uma vez que as práticas lenientes desses escritórios de PI na concessão de marcas comerciais continuam ocorrendo sem nenhuma alteração, ou seja, o atual quadro de vigência da propriedade intelectual continua aberto a abusos, mostrando a fratura existente entre os diferentes modos de se apropriar nessa zona de contato entre a propriedade intelectual e os direitos consuetudinários e normas culturais das populações tradicionais.

Esse fato releva que o pouco cuidado na definição e regulamentação dos direitos de propriedade intelectual nos países industrializados não é por acaso, mas sim uma estratégia que visa atender aos interesses comerciais desses países, sustentando as ações de inventoresusurpadores. Em termos internacionais, a repercussão do caso do cupuaçu ganhou pouca atenção, além de engrossar as listas de casos de biopirataria de algumas ONGs internacionais e ganhar notas secundárias em algumas agências de notícias, ainda em termos internacionais. Cabe afirmar que na academia sua repercussão foi quase nula, pois são pouquíssimos os trabalhos que retratam o caso. Uma exceção nesse sentido é o trabalho elaborado por Pantoja e Tapajós (2007), que narra a experiência dos autores como protagonistas-chave na campanha contra a biopirataria realizada pela AMAZONLINK.

Entretanto, deve-se destacar o papel pioneiro protagonizado pela campanha "O cupuaçu é nosso!”, uma vez que, até então, a sociedade brasileira nunca havia discutido a questão da biopirataria com essa mesma profundidade e intensidade. Além de incluir a questão da gestão dos recursos genéticos e saberes tradicionais na pauta de discussão, houve também a divulgação de diversos casos de biopirataria semelhantes, como a do açaizeiro (Euterpe oleracea, Mart.), andiroba (Carapa guianensis Aubl.), copaíba (Copaifera langsdorffii Desf.), kampô (Phyllomedusa bicolor), etc.

Um dos desdobramentos do caso do cupuaçu foi uma lista com nomes populares e científicos de diversas espécies frutíferas e medicinais da flora brasileira, elaborada pelo INPI, com o intuito de informar os depositantes de patentes e os escritórios de PI dos outros países acerca dos nomes dessas plantas em português e evitar, desse modo, a concessão indevida de novas marcas. Entretanto, atualmente essa lista não se encontra mais disponível no sítio do INPI na internet (www.inpi.gov.br/).

Outra repercussão direta do caso foi de que o INPI regulamentou o art. 31 da Medida Provisória 2.186-16 que buscava enquadrar o procedimento de concessão de patentes de invenção pelo INPI junto à normativa do Conselho de Gestão do Patrimônio Genético (CGEN). Isso foi realizado através da edição da resolução $n^{\circ} 23$ do CGEN, de 28 de dezembro de 2006, que, enfim, harmonizou a atuação da agência nacional de propriedade intelectual com a regulamentação do CGEN. O efeito prático dessa Resolução é que, quando for o caso, a concessão da patente parte do princípio de que o solicitante atendeu os requisitos do CGEN, uma vez que a sua concessão passa a depender também da obediência à legislação de acesso aos recursos genéticos e conhecimento tradicional associado.

Já o projeto Aldeias Vigilantes foi a principal repercussão local do caso de biopirataria envolvendo o cupuaçu. Este projeto foi financiado pelo Ministério do Meio Ambiente (MMA) e pelo Ministério da Justiça (MJ) e teve um caráter educativo e informativo. Ele foi realizado pela AMAZONLINK a partir de 2003 e concluído em meados de 2007. Consistiu, principalmente, de uma divulgação e discussão da legislação de acesso aos recursos genéticos e saber tradicional preconizada pelo CGEN, pela CDB, além de outros direitos indígenas constantes na Constituição Federal junto aos indígenas do estado do Acre, em uma linguagem mais adequada a sua compreensão, ressaltando a importância do combate à biopirataria. 
Discutiam-se adicionalmente outros conceitos-chave para a realização do acesso aos conhecimentos tradicionais, tais como anuência prévia, repartição de benefícios, e os tipos de pesquisa que envolvem saber tradicional. O último ponto a ser tratado nas reuniões era o sistema de informações "aldeias vigilantes", que visou promover a integração das comunidades participantes em uma rede de contatos que atuasse no sentido de denunciar, junto às autoridades do Estado, possíveis casos de acesso indevido ou não autorizado de recursos genéticos ou saberes tradicionais.

As comunidades participantes foram visitadas por membros da AMAZONLINK, que organizavam seminários e oficinas em que se debatia como ocorre a biopirataria na prática, através de oficinas teatrais que simulavam o modus operandi dos biopiratas.

Acredita-se que esse projeto, apesar do seu caráter temporário e essencialmente legalista, seja uma iniciativa favorável para a informação e capacitação dos povos indígenas. Além de valorizar esse saber junto às comunidades, outro ponto positivo observado foi a tentativa de se envolver e integrar os técnicos de diferentes agências governamentais locais (como a Agência Brasileira da Informação, Secretaria Estadual de Meio Ambiente, entre outras) na discussão das maneiras de se evitar e prevenir a ação de biopiratas no Acre.

Em geral, pode-se afirmar que o projeto Aldeias Vigilantes foi um desdobramento positivo do caso do cupuaçu para os povos indígenas do Acre, principalmente pela sua atuação na conscientização da questão da biopirataria, e do valor do saber tradicional. Inclusive acredita-se que a criação da rede de informações para se coibir e evitar a ação local de biopiratas seja uma iniciativa promissora para a redução de casos biopirataria na região.

Por outro lado, além do seu caráter relativamente efêmero - as oficinas duravam no máximo dois dias - questiona-se os efeitos desse projeto tendo-se em vista a resistência e luta desses povos pelo reconhecimento de suas normas consuetudinárias, uma vez que o projeto visava apenas traduzir para a comunidade tanto os conceitos quanto os direitos garantidos pela legislação de acesso.

Já no âmbito da Diretoria do Patrimônio Genético (DPG), esse caso motivou a realização de um levantamento dos casos de apropriação indébita de recursos genéticos brasileiros em nível internacional. Nesse levantamento buscou-se verificar, junto às bases de dados dos escritórios de propriedade intelectual internacionais, se haviam patentes concedidas após a data de edição da MP 2.186-16, em 23 de agosto de 2001, que dispõe sobre o acesso aos recursos genéticos e saberes tradicionais associados no Brasil. As palavras buscadas nas bases de dados foram os nomes científicos e nomes populares de 50 plantas de uso medicinal, cosmético e alimentar nativas, já conhecidas, e que fazem parte da farmacopéia brasileira, tais como jaborandi (Pilocarpus sp.), barbatimão (Stryphnodendron adstringens), graviola (Annona muricata L.) etc.

Isso foi feito a partir da consulta das bases de dados dos escritórios de propriedade intelectual norte-americano, japonês e europeu na internet. Os dados obtidos são impressionantes, pois revelou que, apenas para essas 50 espécies de plantas reconhecidamente brasileiras, existem mais de 2 mil patentes concedidas após a CDB, sem evidência de acordos de anuência prévia ou repartição de benefício.

Só do cupuaçu são 32 patentes no USPTO (United States Patent Office); 29 do jaborandi; marapuama (Ptychopetalum olacoides Benth.), 9; murumuru (Astrocaryum murumuru Mart), 23; e 12 patentes da graviola (Annona muricata L.) concedidas após a CDB. Estes dados revelam a dimensão do fluxo desigual de saberes, recursos genéticos e poder no eixo Norte-Sul. (REZENDE, 2008)

Cabe relembrar que aí não se incluem patentes concedidas antes da assinatura da CDB, realizada em 1992. Mesmo assim, encontrar mais de 2.000 patentes para pouco mais de cinquenta 
plantas levantadas nesse período de 14 anos mostra a dimensão dos abusos que vêm sendo cometidos no atual sistema de propriedade intelectual.

Ressalta-se ainda que essa busca partiu apenas dos nomes científicos e comuns de 50 plantas nativas brasileiras, que já têm o uso difundido. Essa busca não cobriu nomes de princípios ativos ou outros compostos e partes derivados destas plantas, como, por exemplo, genes, ou tampouco o saber tradicional relacionado a esses recursos. De maneira adicional, os dados dessas patentes irregulares levantam uma grande preocupação com a biopirataria dos demais elementos da rica biodiversidade brasileira, incluindo-se microorganismos, animais, além daquelas plantas ainda não descritas pela ciência e/ou não inclusas na pequena lista verificada pelo DPG-MMA.

Mesmo que essas patentes levantadas na pesquisa não tenham gerado efetivamente um produto ou processo para o mercado, elas, em tese, preservam os direitos de seus titulares ou pseudo-inventores, pois, no sistema de propriedade intelectual, o ônus da quebra da patente recai sobre as pessoas que contestam a concessão do direito, funcionando efetivamente como barreira à entrada de demais interessados em desenvolver produtos e processos à partir destes recursos genéticos brasileiros.

Enfim, esse contexto mostra que o governo brasileiro tem falhado em proteger esses recursos e saberes de valor estratégico na era da economia informacional, ferindo a soberania do país sobre seus recursos genéticos, preconizada pela CDB, pela MP 2.186-16 e pela própria Constituição, em seus artigos 216 e 225.

Também pode-se observar que o atual sistema de propriedade intelectual tem operado no sentido de encorajar a apropriação indébita do saber tradicional, avançando paulatinamente seu escopo de ação também sobre este domínio da vida, como uma reedição atualizada do episódio histórico do cercamento dos comuns, ocorrido na Inglaterra durante a primeira revolução industrial.

Talvez, por ocasião da publicação futura desses dados pelos veículos de comunicação de massa, a repercussão desses usos e abusos através das patentes gere um momento político capaz de favorecer a discussão da questão do acesso aos saberes tradicionais e recursos genéticos, bem como o questionamento, em bloco, das patentes e marcas concedidas indevidamente.

\section{CONSIDERAÇÕES FINAIS}

O Brasil tem a mais avançada implementação da CDB em nível nacional no mundo; mesmo assim, essa resposta legislativa e institucional que busca regulamentar o acesso aos recursos genéticos e saber tradicional associado tem falhado ao tentar protegê-los da ação de biopiratas.

O caso do cupuaçu tratado aqui revela apenas a "ponta do iceberg" da dificuldade em proteger o saber tradicional. O controle da propriedade intelectual obtida a partir da pesquisa desse tipo de recurso e saber acessado ilegalmente no Brasil ainda não desencadeou ações práticas que coíbam esses abusos em nível nacional e internacional.

Essa breve discussão evidencia um cenário político cada vez mais incerto para o reconhecimento dos direitos de autodeterminação e consuetudinários, manutenção dos estilos de vida e posse dos territórios das populações tradicionais e povos indígenas.

A falta de controle se deve tanto à falta de critérios legais que caracterizem o crime de biopirataria quanto à limitação dos atuais instrumentos de gestão do saber tradicional em conferir uma proteção mais efetiva. 
Levantou-se a questão da validade de muitas solicitações atuais de registro de patentes que alegam "passo inventivo", mas que, na verdade, representam um abuso legal e econômico e um desrespeito às inovações e práticas das populações originalmente detentoras desse saber. Esta análise, agregada à discussão do caso do cupuaçu, permitiu a discussão dos efeitos da PI sobre o saber tradicional, ou de sua impropriedade.

Esse quadro, associado às acusações de biopirataria, tem criado um clima de grande desconfiança entre pesquisadores e populações tradicionais, e também entre as próprias populações tradicionais. Desse modo, enquanto alguns se apressam em proclamar o fim da Etnobotânica (THE ECONOMIST, 1999, apud MAFFI, 2004, p. 21), outros já analisam essa nova encruzilhada em que se inserem as atividades dos pesquisadores (POSEY, 1999; FORD, 2001; ALEXÍADES, 2004), de maneira a sugerir uma nova atitude frente essa realidade.

Segundo Parry (2004), para que esse reconhecimento se concretize é necessária uma mudança de atitude dos pesquisadores frente à biopirataria, no entanto isso também parece um sonho distante:

Possivelmente, isto deve-se porque a maioria dos cientistas que trabalham em agências intermediárias tais como jardins botânicos e museus de história natural preferem ver seu papel mais como um investigador científico do que um subcontratado da indústria ( p. 124).

Nesse contexto, o papel dos profissionais da Etnobotânica, e principalmente da Etnofarmacologia, entre outras áreas do saber, não seria apenas o de documentar usos medicinais específicos das amostras biológicas estudadas, mas também de "persuadir ativamente as populações nativas de que elas se irão beneficiar ativamente dos programas de bioprospecção" (PARRY, 2004, p. 134).

Nessa zona de contato entre o conhecimento científico e o saber tradicional, é inegável que as Etnociências e a própria Antropologia carregam e carregarão alguma esperança para a melhoria das condições de vida das populações estudadas. Isso se deve tanto à sua própria metodologia, que se caracteriza, em grande parte, por práticas participativas, que dão voz à perspectiva das comunidades, quanto à sua distinção êmica-ética, na qual o pesquisador é entendido como um ator sempre capaz de aprender.

Para Sardar, "apenas quando aceitar-se a especificidade que o conhecimento científico tem em nossa cultura, poder-se-á dar mais dignidade às outras formas de se conhecer” (2006, p. 28).

Ao lidar o com dilema da cientifização do saber tradicional via instrumentos de propriedade intelectual, Posey (1999) sugere a necessidade de um modelo de desenvolvimento que leve em conta o elo entre natureza e cultura, característico das populações tradicionais, uma tarefa que incluiria as seguintes ações:

- Conscientizar planejadores e agências de desenvolvimento sobre as implicações do desenvolvimento junto às populações tradicionais através da produção científica;

- Facilitar diálogos entre as populações tradicionais e povos indígenas com mecanismos de solução de conflitos;

- Ajudar a construir uma base moral legal para detentores de saber tradicional ameaçados;

- Facilitar a transmissão do saber tradicional entre gerações e populações que perderam seu território;

- Promover o saber tradicional concedendo bolsas de pesquisa para pesquisadores nativos. (p.27) 
Em adição, Colfer (2005, p. 320) comenta que "juntos, o saber tradicional e o conhecimento científico formam, potencialmente, a combinação mais poderosa para o bem-estar humano e qualidade do meio ambiente". No entanto, tal integração demandaria o reconhecimento do saber tradicional como parte dos direitos das populações tradicionais e povos indígenas sobre seu território e recursos, suas regras costumeiras de uso, bem como o estabelecimento de registros de saber tradicional e fundos, para a repartição de benefícios. De acordo esse autor, essas práticas iriam melhorar os resultados dos esforços de desenvolvimento e conservação, fortalecer e proteger os estilos de vida tradicionais e aumentar a auto-estima e o prestígio das populações tradicionais.

No entanto, com o atual reordenamento do papel das redes PI, tecidas através da sua expansão globalizada, somente uma reflexão que desnaturalize seu aspecto utilitarista permitirá recuperar a dimensão social e política desses saberes para a sociedade como um todo e resguardar a sua existência como fonte de produção de saberes para a vida.

\section{REFERÊNCIAS}

ALEXÍADES, M. N. Ethnobotany and globalization: science and ethics at the turn of the century. In: CARLSON, J. S; MAFFI, L. (Eds.). Ethnobotany and conservation of biocultural diversity. Advances in Economic Botany. New York: The New York Botanical Gardens Press, 2004. p. 140159.

ARROW, K. The economic implications of learning by doing. Review of Economic studies. v. 29, p. 155-73, 1962.

ASEAN. The TRIPs agreement and pharmaceuticals: report of an ASEAN workshop on the TRIPs agreement and it’s impact on pharmaceuticals. Jakarta, Indonesia, 2000. 81 p.

BERKES, F.; COLDING, J.; FOLKE, C. Rediscovery of traditional ecological knowledge as adaptive management. Ecological Applications, v. 10, n. 5, p. 1251-1262, out/2000.

BLAKENEY, M. Intellectual property in the dreamtime: protecting the cultural creativity of the

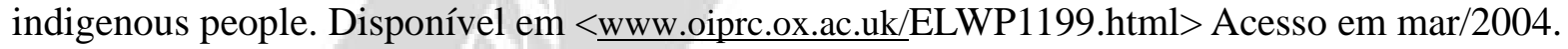

BURKE, P. Uma história social do conhecimento: de Gutenberg a Diderot. Rio de Janeiro: Zahar, 2003. 241 p.

CALZAVARA, B.B.G. Cupuaçuzeiro: recomendações básicas. Belém. EMBRAPA/CPATU, 1987. 5 p.

CASTELLS, M. The informational city. Oxford: Blackwell, 1989. 416 p.

COLFER, C. J. P. The importance of traditional knowledge. In: MERY, G. et al. (Eds.). Forests in the Global Balance: changing paradigms. IUFRO World Series, Helsinki, 2005. V. 17, p. 318335.

COMISSÃO BRITÂNICA SOBRE DIREITOS DE PROPRIEDADE INTELECTUAL. The problem with patents. Londres: CIPR, 2002. 138p. 
CORREA, C. M. Analisando tensões entre patentes e o interesse público: rumo a uma agenda para países em desenvolvimento. In: VILLARES, F. Propriedade Intelectual. Tensões entre o capital e a sociedade. São Paulo: Paz e Terra, 2007, p. 306-331.

DAVID, P. Paul David. Interviews for the future. Munich: European Patent Office, 2006.

DIEGUES, A. C. (Org.). Os saberes tradicionais e a biodiversidade no Brasil. Brasília: MMA, 2000. Disponível em < www.mma.gov.br $>$ Acesso em mar/2002.

DUPAS, G. Propriedade Intelectual: tensões entre a lógica do capital e os interesses sociais. In: VILLARES, F. Propriedade Intelectual.Tensões entre o capital e a sociedade. São Paulo: Paz e Terra, 2007, p.15-24

ELLEN, R. F.; HARRIS, H. Introduction. In: ELLEN, R. F.; PARKERS, P. and BICKER, A. (Ed.). Indigenous environmental knowledge and its transformations: critical anthropological perspectives. Amsterdam: Harwood, 2000. p. 1-33.

FARNSWORTH, N. R. Testando plantas para novos medicamentos. In: WILSON, E. O. (Ed.). Biodiversidade. Rio de Janeiro: Nova Fronteira, 1997. p. 107-125.

FORD, R. I. Introduction: Ethnobiology at the crossroads. In: (Ed.). Ethnobiology at the millennium: past promise and future prospects. Michigan: Museum of Anthropology, 2001. p. 19.

FRAIFE FILHO, G. A. Histórico da introdução do cupuaçu sem sementes no estado da Bahia. A Tarde Rural, v. 10, p. 8-10, set/2000.

FRANCO, A. A. M. O índio brasileiro e a revolução francesa: as origens brasileiras da teoria da bondade natural. Rio de Janeiro: Topbooks, 1976. 318 p.

GANDELMAN, M. Poder e conhecimento na economia global. Rio de Janeiro: Civilização Brasileira, 2004. 317 p.

HUMPHREY, C.; VERDERY, K. Introduction: raising questions about property. In: (Eds.). Property in question: value transformation in the Global Economy. Nova Iorque: Wenner Gren International Symposium Series, 2004. p. 1-25.

JOHNSON, B.; LUNDVALL, B. A. Promoting innovations systems as a response to the globalising learnig economy. Nota técnica 4. Grupo de estudos em inovação. Rio de Janeiro: UFRJ, 2000.

KRECH, S. The ecological Indian: myth and history. Nova Iorque: W. W. Norton, 2000. 318 p.

LEONEL, M. Bio-sociodiversidade: preservação e mercado. Estudos Avançados, v. 14, n. 38, p. 321-345, 2000.

LOPES, J. R. M; LUZ, E. D. M. N; BEZERRA, J. L. Situação atual do cupuaçuzeiro no Sul da Bahia. Agrotrópica, Ilhéus, v. 11, n. 3, p. 183-188, set/1999.

LUNDVALL, B. A. The learning economy: challenges to economic theory and policy. In: EAEPE - Conference, Copenhagen, 1994, 23p.

MAFFI, L. Maintaining and restoring biocultural diversity: the evolution of a role for ethnobiology. In: CARLSON, T. J. S.; MAFFI, L. (Eds.). Ethnobotany and the conservation of 
biocultural diversity: advances in economic botany. V. 15. Nova Iorque: The New York Botanical Gardens, 2004. p. 9-35.

OMPI, Fields of intellectual property protection. Disponível em $<\underline{w w w . w i p o . o r g}>$ Acesso em nov/2003.

PANTOJA, E. S.; TAPAJÓS, S.I.L. As ONGs e a proteção da biodiversidade brasileira: sua contribuição social e política. T\&C Amazônia, v.4, n. 10, fev/2007.

PARRY, B. Trading the genome: investigating the commodification of bio-information. Nova Iorque: Columbia University Press, 2004. 319 p.

POSEY, D. A. Introduction: culture and nature - the inextrincable link. In: Cultural and spiritual values of biodiversity. Nairobi, UNEP: 1999. p.1-18.

POSEY, D. A; DUTFIELD, G. Beyond intellectual property: Toward traditional resource rights for indigenous people and local communities. Ottawa: IDRC, 1996. 281 p.

POSSAS, S. Concorrência e competitividade: notas sobre estratégia e dinâmica seletiva na economia capitalista. Campinas: Hucitec, 1999. 120 p.

REZENDE, E. A. Biopirataria ou bioprospecção? Uma análise crítica da gestão do saber tradicional no Brasil. Tese de Doutorado (Administração), Escola de Administração, Universidade Federal da Bahia, 2008. 416 f.

RIBEIRO, G. D. A cultura do cupuaçuzeiro em Rondônia. 2. ed. Porto Velho: Embrapa Rondônia, 1992. 30 p.

RIFKIN, J. O século da biotecnologia. São Paulo: Makron, 1999. 290 p.

SÁDABA, I. Propriedad intelectual. Bienes públicos o mercancias privadas? Madrid: Catarata, 2008. 273 p.

SANTOS, L. G. A biodiversidade e a questão dos direitos intelectuais: ambiente e sociedade. São Paulo: Unicamp, 1997. Ano 1, n. 1.

SARDAR, Z. When knowledge is not the answer. New Statesman, Londres, 12/ jun/2006. p. 28.

SCHOLZ, A. J. From molecules to medicines. In: GOODMAN, A. H.; HEATH, D.; LINDEE, S. (Eds.). Genetic nature/culture: antropology and science beyond the culture divide. Berkeley: University of California, 2003. p. 195-217.

SEINI, M. M. Bioprospecting and access to indigenous flora: policy implications of contested ways of 'knowing' and 'owning'. 303 f. Tese (Ciências Políticas), School of Social Science, Griffith University, 2003.

SHERWOOD, R. M. Propriedade intelectual e desenvolvimento econômico. São Paulo: Edusp, 1992.

SILLITOE, P.; BICKER, A. Introduction: hunting for theory, gathering ideology. In: BICKER, A.; SILLITOE, P.; POTTIER, J. Development and local knowledge. Londres: Routledge, 2004. p. 1-18. 